\title{
Notas sobre los alcances del Artículo 1784 del Código Civil y la responsabilidad del contratista
}

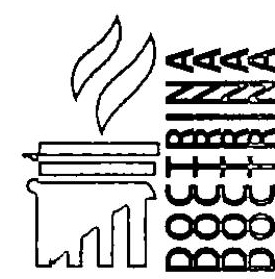

\section{Marco Antonio Ortega Piana}

Abogado por la Pontificia Universidad Católica del Perú. Profesor de Derecho Civil Patrimonial en la Universidad de Lima. Miembro del Consejo Consultivo de la Revista ADVOCATUS.

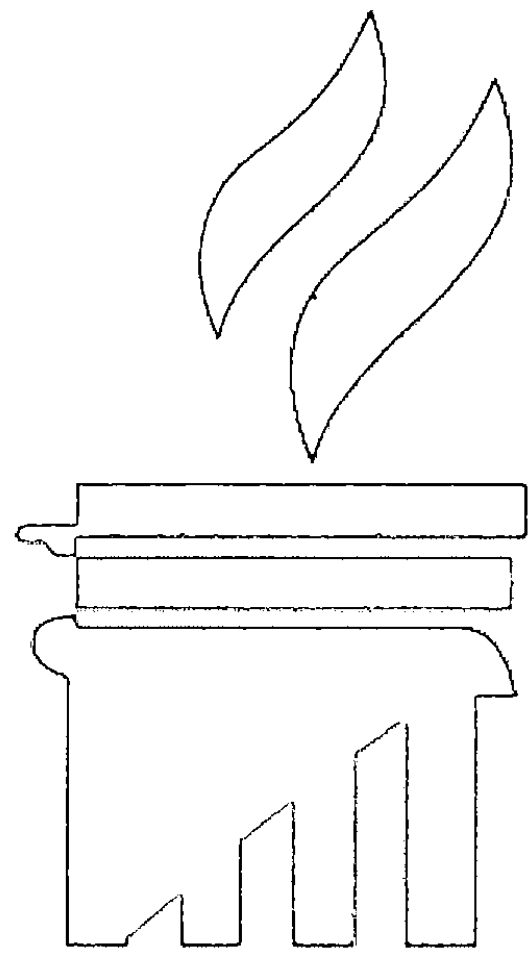

SUMARIO:

I. Introducción.

II. Delimitando el marco legal.

III. Desagregando los alcances de la norma.

IV. Comentario Final. 
"Mis opiniones y convicciones ganan en solidez y aceptación desde el momento en que, luego de confrontadas, una segunda persona las adopta por suyas"

NOVALIS

\section{INTRODUCCIÓN}

En rigor, una vez que se ha generado el vínculo obligacional, el contrato decae por haber cumplido con su objeto, de manera que lo que subsiste entre las partes es una relación jurídica' que, en razón de la naturaleza de las prestaciones comprometidas, se agotará inmediatamente o cuya ejecución se prolongará en el tiempo. La obra es precisamente un contrato que conlleva la necesidad de un plazo de ejecución dentro del cual el contratista pueda cumplir con el encargo recibido del comitente.

Pero la temporalidad de la obra se extiende inclusive a las garantías a cargo del contratista, lo cual tiene como fundamento que la obra está destinada-por lo general-a durar en el tiempo, en mayor o menor medida según sus características. El plazo es pues inherente al contrato de obra, en especial "(...) tratándose de un edificio o de un inmueble destinado por su naturaleza a larga duración (...)", conforme es enunciado en el artículo 1777 del Código Civil con relación a la facultad inspectiva del comitente.

Toda obra significa un hacer que conforme a nuestra legislación civil culmina en un dar, esto es, en lo que se denomina entrega (por parte del contratista) o recepción (por parte del comitente). La recepción de la obra, con su consiguiente aceptación por parte del comitente, tiene una singular importancia porque representa la oportunidad en la cual el contratista acredita su cumplimiento y descarga su responsabilidad en dos aspectos muy precisos: riesgos y vicios. En lo concerniente a los riesgos, si la obra ya entregada se destruye o deteriora, corresponderá al comitente asumir la pérdida física y el costo que ello represente, salvo que demuestre que esa destrucción o deterioro se deriva de un vicio constructivo, presumiéndose la imputabilidad del contratista. En el caso de los vicios, se entiende que el descargo de responsabilidad al momento de la recepción-por la naturaleza de las cosas-solo opera tratándose de los defectos aparentes o inmediatamente constatables por el comitente, de tal manera que subsiste la facultad para reclamar respecto de los vicios ocultos, sea a título de saneamiento o bajo el título de determinado régimen de responsabilidad contractual, en la medida que se cumplan con los requisitos normativos correspondientes.

De otro lado, merece destacarse que el contrato de obra se encuentra regulado, por normatividad específica del derecho común, en los artículos 1771 al 1789 del Código Civil, siendo además que en el ámbito de la contratación pública, existe regulación específica en la aún vigente Ley de Contrataciones y Adquisiciones del Estado (Texto Único Ordenado aprobado por Decreto Supremo No. 083-2004-PCM) y en su reglamento (aprobado por Decreto Supremo No. 084-2004-P(M), asi como en la nueva Ley de Contrataciones del Estado (Decreto Legislativo 1017) y en su respectivo reglamento (aprobado por Decreto Supremo No. 184-2008-EF) ${ }^{2}$; no obstante lo anterior, también debe destacarse que mientras abunda literatura sobre la parte general de contratos o sobre los procesos de selección para fines de contratar con el Estado, se advierte su ausencia tratándose de ciertas modalidades contractuales, como es el caso de la obra, y de manera particular, de la obra pública, lo cual genera la necesidad de proponer enfoques y un mayor análisis para intentar

1 MESSINEO, Francesco, Doctrina General del Contrato, Tomo I, Ediciones Juridicas Europa-América, Buenos Aires, 1986, p. 45.

2 Normas cuya entrada en vigencia está sujeta a lo establecido en la Décimo Segunda Disposición Complementaria Final del Decreto Legislativo 1017. 
delimitar los supuestos de aplicación de las respectivas normas.

Atendiendo a las reflexiones compartidas en el aula universitaria y a las argumentaciones expresadas en diversos casos en los cuales hemos estado profesionalmente involucrados, y agradeciendo nuevamente a ADVOCATUS por su generosa publicación, el presente ensayo tiene por objeto analizar al artículo 1784 del Código Civil, el cual corresponde a la denominada responsabilidad del contratista, sea quinquenal en el ámbito de la contratación privada, o septenal tratándose de la contratación pública (artículo 51 del T.U.O. de la Ley de Contrataciones y Adquisiciones del Estado, vigente a la fecha). ${ }^{3}$ Estamos seguros que, en general, dicho análisis se puede realizar desde diversas perspectivas académicas, unas con mayor rigurosidad que otras; empero, optamos por la ensayística ${ }^{4}$ como la más apropiada para compartir nuestras inquietudes, ya que lo que nos interesa finalmente es motivar una reflexión sobre cómo entender los alcances del artículo 1784 del Código Civil.

\section{DELIMITANDO EL MARCO LEGAL}

1. Entregada la obra se genera un régimen especial de responsabilidad, regulado por el Código Civil conforme a lo siguiente:

\section{"Artículo 1784.-Responsabilidad del contratis- ta por destrucción vicios o ruina}

Si en el curso de los cinco años desde su aceptación la obra se destruye, total o parcialmente, o bien presenta evidente peligro de ruina o graves defectos por vicio de la construcción, el contratista es responsable ante el comitente o sus herederos, siempre que se le avise por escrito de fecha cierta dentro de los seis meses siguientes al descubrimiento. Todo pacto distinto es nulo.

El contratista es también responsable, en los casos indicados en el párrafo anterior, por la mala calidad de los materiales o por defecto del suelo, si es que hubiera suministrado los primeros o elaborado los estudios, planos y demás documentos necesarios para la ejecución de la obra.

El plazo para interponer la acción es de un año computado desde el día siguiente al aviso a que se refiere el primer párrafo".

Dicho artículo, debería leerse e interpretarse -al menos- en el contexto de tres normas adicionales:

"Artículo 1782.- Responsabilidad derivadapor vicios de la obra

El contratista está obligado a responder por las diversidades y los vicios de la obra.

La recepción de la obra, sin reserva del comitente, descarga de responsabilidad al contratista por las diversidades y los vicios exteriores de ésta".

3 Debe destacarse que de acuerdo al artículo 119 del Reglamento de la Ley de Contrataciones y Adquisiciones del Estado, según texto aprobado en su oportunidad conforme al'Decreto Supremo No. 039-98-PCM, la responsabilidad a la que se contrae el artículo 51 de la Ley 26850 (Ley de Contrataciones y Adquisiciones del Estado) correspondía explícitamente al artículo 1784 del Código Civil, manteniéndose la competencia arbitral por más que la liquidación hubiese quedado consentida. Si bien dicha disposición reglamentaria no figura actualmente con el mismo tenor, debe destacarse que el artículo 270 del todavía vigente reglamento de la Ley de Contrataciones y Adquisiciones del Estado (aprobado por Decreto Supremo No. 084-2004-PCM) establece que tratándose de la reclamaciones por defectos o vicios ocultos, las mismas se resolverán siempre mediante conciliación y/o arbitraje, dentro del plazo previsto para ello, esto es, siete años. ¿Bajo qué condiciones? En función a lo dispuesto en el artículo 201 del reglamento en cuestión, dicha responsabilidad será exigible conforme al derecho común. En ese orden de ideas, bien puede concluirse que el artículo 1784 de nuestro Código Civil es una norma de singular importancia tanto en la contratación privada como pública. En la misma línea, se encuentra lo establecido en el artículo 177 del Reglamento de la Ley de Contrataciones del Estado, así como el artículo 50 de esta última, aprobada por Decreto Legislativo 1017.

4 El ensayo es un estilo de expresión escrita, de extensión relativamente breve, mediante el cual se expone, analiza y comenta cierto tema desde la perspectiva del autor, sin un rigurosidad sistemática como sí corresponde a una investigación, por lo que su contenido es esencialmente argumentativo. 
"Articulo 1783.- Acciones del comitente por vicios de la obra

El comitente puede solicitar, a su elección, que las diversidades o los vicios de la obra se eliminen a costa del contratista, o bien que la retribución sea disminuida proporcionalmente, sin perjuicio del resarcimiento del daño.

Si las diversidades o los vicios son tales que hagan inútill la obra para la finalidad convenida, el comitente puede pedir la resolución del contrato y la indemnización por los daños y perjuicios.

El comitente debe comunicar al contratista las diversidades o los vicios dentro de los sesenta dias de recepcionada la obra. Este plazo es de caducidad. La acción contra el contratista prescribe al año de construida la obra".

\section{"Artículo 1785.- Liberación de responsabilida- des del contrato}

No existe responsabilidad del contratista en los casos a que se refiere el artículo 1784, si prueba que la obra se ejecutó de acuerdo a las reglas del arte y en estricta conformidad con las instrucciones de los profesionales que elaboraron los estudios, planos y demás documentos necesarios para la realización de la obra, cuando ellos le son proporcionados por el comitente".

2. Para intentar delimitar los alcances del artículo 1784 del Código Civil debemos partir del concepto de vicio, por cuanto el postulado general de la norma bajo estudio es que el vicio constructivo es lo que explica la destrucción de lo ejecutado, la amenaza de ruina o los graves defectos de la obra.

Vicio es -según reconocida doctrina-cualquier defecto que afecta el valor o la utilidad de un determinado bien. De acuerdo a la normatividad general de contratos, la existencia de ciertos vicios entraña la exigibilidad de la obligación colateral, no nuclear o tipificante del respectivo contrato, consistente en el saneamiento. Debe destacarse que el saneamiento solo resulta exigible tratándose de los denominados vicios ocultos, porque en el caso de los vicios aparentes la solución jurídica es distinta; además, debe considerarse que de conformidad con el artículo 1485 del Código Civil, el saneamiento por vicios ocultos solo es posible respecto de aquellos vicios que "no permitan destinar el bien transferido a la finalidad para la cual fue adquirido o que disminuyan su valor", lo cual significa que debe tratarse de vicios ocultos relevantes, graves, siendo que solo asi se justifica una determinada reacción jurídica que puede derivar inclusive en la resolución contractual, medida extrema por la cual se dejará sin efecto al contrato celebrado.

Habiéndonos referido a los vicios ocultos y aparentes, resulta pertinente definirlos. Son aparentes o externos aquellos defectos o irregularidades inmediatamente verificables con ocasión de la entrega o transferencia del respectivo bien, sea a título de propiedad, posesión o uso (artículo 1484 del Código Civil). Por lo tanto, por una cuestión elemental de diligencia, en el contexto de un contrato de obra, al advertir su existencia, el comitente debe cuidar de dejar constancia de ellos (observaciones) para que sean eliminados por el contratista (subsanación de las observaciones), siendo que la existencia de dichos vicios justifica que no se reciba la obra (o que se realice una recepción a título provisional); en otras palabras, la recepción (definitiva, de ser el caso) solo procederá cuando se subsane la situación defectuosa. Si el comitente recibe la obra sin formular reserva respecto de aquellos defectos que son inmediatamente verificables de manera sensorial, se entiende que consiente en su existencia o, dicho de otra manera, que considera que los mismos no afectan el valor ni la utilidad del bien. Esta situación está recogida en el segundo párrafo del artículo 1782 del Código Civil anteriormente reproducido y no genera mayor comentario porque cada quien debe cuidar de su propio interés, siendo que la conducta observada genera una confianza concluyente. Callar cuando se debe hablar, bajo los postulados de la buena fe contractual que se guía por la apariencia razonable, es aceptar. Y no se trata que el silencio signifique aceptación pura y simple, sino que la aceptación de la obra sin observaciones, como una determinada conducta positiva de recibir algo sin objetarlo, representa una determinada manifestación de voluntad, siendo que luego no corresponderá 
aceptar que el interesado desconozca sus propios actos.

De otro lado, por contraposición a lo anterior (definición negativa), los vicios son ocultos o internos cuando su existencia no puede advertirse inmediatamente con ocasión de recibirse el respectivo bien, siendo que recién se evidencian de manera posterior.

Como el vicio o defecto oculto se manifiesta de manera sobreviniente a la recepción del bien por el comitente, se genera la necesidad de poner un razonable límite temporal para la procedencia de su reclamo o, expresado de otra manera, para hacer efectiva la responsabilidad del contratista. Tratándose de esta clase de defectos debemos destacar dos términos que hemos empleado precedentemente: existencia y evidencia. En efecto, el vicio oculto debe existir al momento de la transferencia (artículo 1503 del Código Civil) o recepción del bien -en el contexto de la obra-, otra cosa es que no se evidencie en dicha oportunidad, dado que se manifestará de manera sobreviniente. El vicio ya existe, pero de manera latente, subyacente.

La cuestión radica en determinar cuándo se entiende que el vicio oculto es verificable. De acuerdo al artículo 1504 del Código Civil el adquirente debe hacer uso de "la diligencia exigible de acuerdo con su aptitud personal y con las circunstancias" (en el caso del contrato de obra se entiende que la referencia corresponde al comitente). ¿Qué significa eso? ¿Qué la diligencia se va a examinar en términos absolutamente subjetivos en función de la persona específica o de las circunstancias que la rodean? Al efecto, consideramos que debe recurrirse a un estándar o patrón de conducta abstracto para comparar la actuación concreta, lo que generará un efecto beneficioso en cuanto la necesaria seguridad jurídica. ¿El defecto hubiese sido verificable por cualquier individuo en iguales condiciones personales al presunto perjudicado, atendiendo a las mismas circunstancias de actuación respecto a los hechos? Ello determinará si el comportamiento del comitente fue diligente o culposo. Si se concluye, luego de la respectiva calificación jurisdiccional, que se actuó por debajo del estándar de conducta esperada, de las revisiones o verificaciones mínimas que se esperaban o que hubiesen sido hechas por una persona razonable atendiendo a su interés en recibir la obra, ello significará que el comitente estuvo en capacidad de advertir el defecto ( $y$, por lo tanto, que el vicio no era oculto), por lo que al haber recibido el bien sin formular observación, renunció implícitamente a cualquier reclamación respecto al vicio en cuestión. Por el contrario, si se concluye que la actuación fue la normal o esperada, con la diligencia del caso, bajo el cuidado esperado y exigible a cualquier individuo bajo las mismas circunstancias de personas, tiempo y lugar (artículo $1320 \mathrm{del}$ Código (ivil), ello determinará que el vicio no era verificable de manera inmediata, por lo que de comprobarse posteriormente su existencia, el adquirente o, en nuestro caso, el comitente, mantendrá su derecho facultativo para reclamar el respectivo saneamiento, por cuanto se le ha entregado finalmente algo que no corresponde a lo esperado.

3. Siempre con el propósito de delimitar los alcances y la aplicación misma del artículo 1784 del Código Civil, merece analizarse el contenido del artículo 1783 del mismo cuerpo normativo.

En nuestra opinión el señalado artículo 1783 regula dos situaciones distintas: vicios aparentes y vicios ocultos. Sus dos primeros párrafos se refieren a los vicios externos (aparentes); $\sin$ embargo, su tercer párrafo solo puede entenderse referido a los vicios internos (ocultos). Para dicho efecto debe considerarse los alcances del segundo párrafo del artículo 1782 del Código Civil: "La recepción de la obra, sin reserva del comitente, descarga de responsabilidad al contratista por las diversidades y los vicios exteriores de ésta", y es que de haberse verificado la recepción de la obra, sin haberse formulado reservas u observaciones, solo serán reclamables posteriormente los vicios ocultos, entendiéndose que no habría habido vicios aparentes (o que, habiéndolos, no eran significativos para el comitente). No tendría mayor sentido que el Código Civil estableciera, de un lado (artículo 1782), que la recepción sin reservas descarga la responsabilidad por vicios 
externos $y$, de otro lado (artículo 1783) que permita que estos últimos defectos puedan ser reclamados pese a que ya se produjo la recepción (que descarga responsabilidad, conforme ya hemos destacado). Por elemental exclusión, ambas normas no pueden referirse a lo mismo, de manera que por interpretación sistemática debería considerarse que el tercer párrafo del artículo 1783 del Código Civil regula a los defectos ocultos y no a los aparentes.

Es más, si proseguimos con nuestra propuesta de lectura sistemática, ¿No postula el artículo 1777 del Código Civil que la facultad inspectiva, tratándose de edificios e inmuebles destinados a larga duración, debe realizarse por personal técnico calificado?, y aunque el Código Civil no lo señala expresamente, ¿No debería aplicarse la misma exigencia tratándose de la comprobación o examen final previo a la recepción del bien, y consiguiente posibilidad de aceptación? Considerando que, conforme propondremos más adelante, la responsabilidad quinquenal debería entenderse referida esencialmente a la construcción inmobiliaria, una vez producida la aceptación-expresa o tácita-de la obra, ¿Puede sostenerse seriamente que, no obstante la presencia de personal técnico calificado y su asentimiento respecto a las características del bien recibido, el comitente todavía puede reclamar por aquello que no objetó en su oportunidad? De ser así, ¿Qué sentido tendría la comprobación, para qué operaría la aceptación, para qué la ley señala que el comitente debe asistirse del concurso de especialistas (personal técnico calificado)?

Ahora bien, de referirse efectivamente el último párrafo del mencionado artículo 1783 a los vicios ocultos o internos de la obra, se establece un régimen especial para el respectivo saneamiento.

En efecto, de acuerdo al artículo 1514 del Código Civil, "Las acciones a que se refieren los artículos 1511 y 1513 caducan a los tres meses si se trata de bienes muebles y a los seis, de inmuebles. Los plazos se computan desde el momento de la recepción del bien". Tanto el artículo 1511 como el 1513 se refieren al saneamiento por vicios ocultos, siendo que el primero de los señalados artículos regula a la denominada acción redhibitoria (que conlleva la resolución contractual) y el segundo la estimatoria (que solo entraña reajuste prestacional). En otras palabras, conforme a las disposiciones generales sobre contratación, la obligación de saneamiento por vicios ocultos caduca a los tres meses tratándose de muebles y a los seis, tratándose de inmuebles, computándose ambos plazos desde la recepción del bien. El tema es incontrastable. Nos interesa destacar en particular el caso de los inmuebles: la norma general sobre contratación establece seis meses desde la recepción para reclamar el saneamiento, y nos interesa porque es un plazo más extenso que tratándose de los muebles (una nueva muestra del obsoleto criterio legislativo de subvalorar a los bienes muebles) y porque se aplica precisamente a los bienes como "(...) tratándose de un edificio o de un inmueble destinado por su naturaleza a larga duración (...)" a los cuales se refiere determinada regulación del contrato de obra, tema que comentaremos más adelante.

Sin embargo, la disposición especial en materia de obra (tercer párrafo del artículo 1783 del Código (ivil), seguramente debido a que es justamente la obra la que se constituye como objeto mismo del respectivo acuerdo (más aún cuando gran parte de la regulación del contrato de obra corresponde a la construcción, tema que comentaremos en su momento de manera más amplia), establece un régimen temporal distinto de responsabilidad por vicios ocultos, consagrando que la prescripción opera al año de construida la obra, al margen de su naturaleza mobiliaria o inmobiliaria, aunque ordinariamente sea este último el caso.

De dicha disposición especial nos llama la atención la referencia para el inicio del cómputo del plazo de prescripción anual. El tercer párrafo del artículo 1783 del Código Civil no se refiere a la recepción de la obra (como sí lo hace la norma general en materia de contratación, especificamente sobre saneamiento) sino a la oportunidad de construida, esto es, al momento en que se tiene por construida. 
Somos de opinión que por una cuestión de certidumbre la oportunidad en que se tenga por construida la obra debe entenderse jurídica antes que fácticamente, por lo que la obra estará construida para el comitente desde que la acepta, una vez que se ha concluido y la recibe. Pero la respectiva acción, sujeta al plazo prescriptorio anual, a su vez está condicionada legalmente a que dentro de los sesenta días (no dos meses, conforme a las reglas de cómputo de plazos contenidas en el artículo 183 del Código Civil) de recibida la obra el comitente comunique al contratista los vicios detectados, aquello que dejó de ser oculto y adquiere el carácter de manifiesto, siendo de caducidad dicho plazo, esto es, su inobservancia deriva en la extinción del derecho mismo a reclamar. Expresado en otros términos, si el comitente reclama saneamiento, dispone de sesenta días desde la recepción de la obra para dar aviso del vicio oculto. Si el comitente no comunica oportunamente el vicio oculto, caduca su derecho para reclamar el respectivo saneamiento. Si el vicio oculto se manifiesta una vez vencido el indicado plazo de sesenta días, no procede saneamiento alguno. Ahora bien, comunicado oportunamente el vicio oculto, ello permite mantener la facultad de exigir el saneamiento, la acción prescribe al año.

Se sostiene que el plazo (anual) para el ejercicio del reclamo debería ser de caducidad, al igual como lo es el plazo para el aviso (sesenta días), cuestionándose que el Código Civil les asigne naturaleza distinta. ${ }^{5}$ No vemos la razón. En nuestra opinión la solución legislativa de la prescripción (anual), sobre la base que se haya remitido oportunamente el aviso de la comprobación del vicio oculto, es coherente con los conceptos de prescripción y caducidad contenidos en el Código Civil (más allá que podamos discrepar $\left.{ }^{6}\right)$, porque la prescripción presupone el mantenimiento del derecho ante la extinción de la acción (artículo 1989 del Código Civil), de manera que si bien el comitente no podrá exigir jurisdiccionalmente al contratista el respectivo saneamiento (ya no existe deber jurídico como contrapartida del derecho subjetivo), nada impide que el contratista pueda asumir volun-

5 ARIAS-SCHREIBER, Max y CARDENAS, Carlos, con la colaboración de ARIAS-SCHREIBER, Ángela y MARTINEZ, Elvira, Exégesis del Código Civil peruano de 1984, Tomo III, Gaceta Jurídica Editores, Lima, 1997, p. 128. El argumento expresado radica textualmente en: "(...) habida cuenta de la politica general seguida por el Código en cuanto se refiere a la continuidad del contrato", argumento que es reproducido por TOVAR, María del Carmen y FERRERO, Verónica, al comentar los alcances del articulo 1783 del Código Civil en la obra colectiva Código Civil comentado, Tomo IX, Gaceta Jurídica S.A., Lima, Segunda Edición, Primera Reimpresión, 2007, p. 180, por lo que pueden inferirse que también lo suscribirían.

6 Resulta útil remitirnos al trabajo de ESCOBAR, Freddy, El débito y la responsabilidad en la estructura de la obligación: Historia de una confusión, contenido en su libro Teoría general del Derecho Civil (5 ensayos), Ara Editores E.I.R.L., Lima, 2002, pp. 57 a 121. Se aprecia que existe una posición que identifica a los derechos prescritos como obligáciones naturales, casos de débito sin responsabilidad, para justificar la inaplicación del pago indebido (artículo 1275 del Código Civil), ya que habría pre-existido una relación, de la cual solo subsiste el débito; empero, como manifiesta el señalado autor, en realidad con todo ello se genera una confusión conceptual. Toda obligación es como una medalla, cuyo anverso es el derecho subjetivo y su reverso es el respectivo deber jurídico como contrapartida necesaria; la inexistencia de uno de ellos genera que no estemos propiamente ante una obligación. No hay débito sin responsabilidad, por lo que la inaplicación del pago indebido debería justificarse mediante otros argumentos, como puede ser simplemente una asignación directa, originaria, de ciertos efectos por el Derecho por múltiples consideraciones. De lo anterior puede entonces concluirse, dándose un paso más, que la pretendida diferencia entre prescripción y caducidad, sustentada en situaciones de débito sin responsabilidad, no se justificaría, por lo que las diferencias entre ambas deben explicarse sobre la base de argumentos distintos, como podría ser el tema de la procedencia de supuestos de suspensión e interrupción en cuanto al cómputo de sus plazos, etc. Nos interesa destacar que este planteamiento, conforme al cual no hay débito sin responsabilidad, pero que sí puede haber situaciones de responsabilidad sin débito, como es el caso de las garantías reales constituidas por terceros (aunque hay quienes niegan inclusive esta última posibilidad), evidencia que el contenido conceptual de ciertas figuras e instituciones siempre es susceptible de revisión y replanteo, ya que en el Derecho no hay uno sino diversos enfoques, que responderán adecuadamente nuestras preguntas en la medida que hayamos estimulado en mayor o menor medida nuestras inquietudes. 
tariamente su responsabilidad pese a que el comitente ya carece de acción para obligarlo. De operar la caducidad no habría la posibilidad de dicha asunción.

De admitirse finalmente que el artículo 1783 del Código Civil regula aspectos relacionados a la reclamación por vicios aparentes (dos primeros párrafos) y por vicios ocultos (último párrafo), entonces, ¿Qué es lo que regula el artículo 1784 del indicado cuerpo legal?, ¿Puede sostenerse que regula el régimen de los vicios ocultos en el caso del contrato de obra o, planteándose la cuestión de otra manera, que los artículos 1783 y 1784 regulan, a los vicios aparentes y a los vicios ocultos, respectivamente?

Postulamos la tesis conforme a la cual el artículo 1784 del Código Civil no regula propiamente ni a los vicios ocultos ni al correspondiente saneamiento en materia del contrato de obra, aunque ello no significa que no se refiera a una situación asociada a los vicios ocultos.

Nos explicamos. Tratándose del contrato de obra el régimen legal sobre vicios ocultos puede explicarse conforme a lo siguiente: a) Si el vicio es aparente o externo, el mismo debe ser invocado a más tardar con ocasión de la recepción de la obra, de lo contrario el silencio tiene un significado muy preciso, implica aceptación sin reservas, porque el comitente debió dejar constancia del vicio. Por lo tanto, una vez recibida la obra, ya no hay posibilidad de invocar vicios aparentes o externos. La norma pertinente es el artículo 1782 del Código Civil; b) Si luego de recibida la obra se manifiesta un vicio, sobre la base que el mismo se hubiese configurado a la fecha de entrega del bien pese a que en esa oportunidad era inadvertible, el comitente puede reclamar por vicios ocultos o internos (graves, por cuanto deben afectar el valor o la utilidad del bien conforme al artículo 1505 del Código (ivil); para dicho efecto, se aplica el tercer párrafo del artículo 1783 del Código Civil, cuyos alcances - por especialidad-determinan la inaplicabilidad del artículo 1514 del mismo cuerpo legal. Este artículo 1783 bajo comentario es particularmente relevante, porque inclusive determina una prelación de la acción estimatoria frente a la redhibitoria, lo cual no está previsto en las normas generales sobre saneamiento por vicio oculto, pero que guarda plena concordancia conceptual con el requisito de gravedad del incumplimiento para fines de optar por la resolución, dado que el legislador se inclina por la preservación del vínculo.?

¿Por qué sostenemos que el artículo 1784 del Código Civil no regula al saneamiento por vicios ocultos, sino que más bien se refiere a una situación asociada a los vicios ocultos? Porque la norma en cuestión establece un régimen de responsabilidad excepcional que va más allá del saneamiento por vicio oculto; se refiere a la garantía implícita en todo contrato de obra, y en particular tratándose de la construcción, que lo ejecutado debe tener durabilidad, permanencia temporal. En ese sentido es que la norma bajo comentario dispone que el contratista está sujeto a un régimen de responsabilidad quinquenal en caso que la obra se destruya (daño cierto, presente), total o parcialmente, amenace destruirse (daño cierto, futuro) o presente graves defectos por vicios constructivos.

Conforme se aprecia de la redacción del artículo en cuestión, no es que se regule el tema de los vicios ocultos, o los alcances de su saneamiento (cuya exigencia está sujeta, reiteramos, a la temporalidad prevista en el tercer párrafo del artículo 1783 del Código Civil), sino que se regula más bien el régimen de responsabilidad contractual en el escenario de destrucción, amenaza de ruina o grave defecto constructivo, no perceptible desde luego con ocasión de la recepción, de alli que la causa sea un vicio oculto. Por lo tanto, no es que se abra la posibilidad para el comitente de reclamar saneamiento por vicios ocultos, porque eso significaría en los hechos olvidar que ya operó la respectiva prescripción anual, sino de reclamar por la ruina de

7 MESSINEO, Francesco, Op. Cit., Tomo II, p. 348. 
lo ejecutado, la amenaza de destrucción o por sus significativos defectos, todo ello derivado de un vicio constructivo que no solo debe ser grave por su naturaleza sino oculto, porque si se tratase de un vicio externo, advertible con ocasión de la recepción del bien, resultaría lógico sostener que el comitente habría asumido implícitamente el riesgo de una eventual ruina o destrucción, o de graves defectos que afecten el uso o el valor del bien.

Atendiendo a lo expuesto, sobre la base que el régimen legal de inejecución de obligaciones es subjetivo, estructurado sobre la noción de culpa, siendo que la misma además se presume a título de culpa leve (artículo 1329 del Código Civil), debe entenderse que el artículo 1784 bajo comentario presume la culpa del contratista en caso de destrucción, amenaza de destrucción o graves defectos de la obra, por lo que para quebrar dicha presunción deberá demostrarse que hubo una ejecución contractual diligente, con arreglo a las "reglas del arte", conforme se enuncia en el artículo 1785 del Código Civil, reproducido en un inicio. En razón de lo anterior, se presumirá que hubo culpa del contratista en la construcción, en la selección de los materiales que hubiese proporcionado o en el diseño que hubiese elaborado, según sea el caso; corresponderá que el contratista demuestre lo contrario, esto es, que desempeñó el servicio conforme a los estándares admitidos, a las especificaciones técnicas, a las instrucciones recibidas, etc. o de ser el caso, que los materiales proporcionados eran idóneos, o que los estudios y planos desarrollados eran adecuados, sin objeción técnica.

Otro tema será analizar cuál es el contenido específico de la garantía del contratista, esto es, cuáles son los alcances de la responsabilidad contractual que le puede ser reclamada por el comitente.

Al respecto, anticipamos nuestra tesis en el sentido que el contenido de dicha responsabilidad no puede confundirse con el saneamiento (limitado a las acciones redhibitoria y estimatoria), no solo porque el artículo 1784 del Código Civil no lo regula, sino porque podría darse el caso que ya hubiese operado la respectiva prescripción, lo cual significa que se extinguió definitivamente la acción. En dicho sentido, postulamos que este régimen de responsabilidad -que solo se aplica en caso que la destrucción o amenaza de ruina de lo construido, o sus graves defectos, se deriven de vicio de la construcción (vicio oculto), o por defecto de los materiales empleados (si hubiesen sido proporcionados por el contratista) o del suelo (si el contratista hubiese elaborado los estudios, planos y demás documentos necesarios para la ejecución de la obra)- posee reglas propias, tema que analizaremos más adelante.

\section{DESAGREGANDO LOS ALCANCES DE LA NORMA}

1. Sobre la base que el artículo 1784 del Código Civil se refiere a un régimen de responsabilidad contractual distinto al saneamiento por vicios ocultos, debemos comenzar destacando que dicho artículo regula en primer lugar el plazo dentro del cual es exigible dicha responsabilidad, esto es, se refiere al período dentro del cual el comitente mantiene el derecho de reclamar en caso de destrucción del bien, amenaza de destrucción (tema asociado más no identificado necesariamente con la inminencia) o graves defectos del bien. Se ha establecido un período de responsabilidad por cinco años, plazo que se computa desde la aceptación de la obra. Habrá que analizar en cada caso si la indicada aceptación fue expresa o si operó tácitamente.

Al respecto, debemos recordar que, conforme a lo analizado precedentemente, la aceptación genera un doble efecto: descargo del riesgo y de la responsabilidad por vicios aparentes o externos. Por lo tanto, producida la aceptación, no hay posibilidad de reclamar por vicios aparentes; dicho de otra manera, se mantiene el derecho a reclamar por vicios ocultos, aunque para esto último solo se dispone de un año conforme al último párrafo del artículo 1783 del Código Civil, sujeto al cumplimiento de otros requisitos.

¿Se dispone realmente de un año?, ¿O es que se dispone de cinco años cuando el vicio oculto está representado por "graves defectos" de la

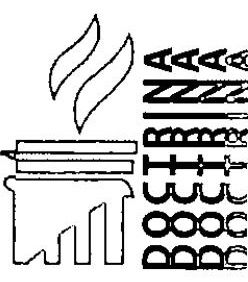


obra por problemas constructivos, conforme se enuncia en el artículo bajo comentario? Por el momento adelantamos nuestra opinión, con cargo a tratar el tema con mayor detalle: los vicios ocultos, y el respectivo saneamiento, solo pueden reclamarse dentro del plazo de prescripción anual; fuera de este último, por más que exista un vicio oculto, resultará extemporáneo reclamar saneamiento (sea a través de las acciones redhibitoria y estimatoria), siendo que más bien (sujeto a ciertos requisitos) se podrá demandar una solución distinta: reparación por daños, lo cual no significa reclamar que se solucione el problema (evento dañoso, como sería la ruina), sino las consecuencias derivadas de su existencia (el perjuicio propiamente, la afectación producida).

Somos de la idea que en función al período de la garantía del contratista, el artículo 1784 (aunque su texto no diga un ápice sobre ello) solo debería aplicarse en los casos de destrucción, amenaza de destrucción o graves defectos "(...) tratándose de un edificio o de un inmueble destinado por su naturaleza a larga duración (...)", esto es, la responsabilidad quinquenal debería relacionarse exclusivamente a las obras consistentes en construcción con vocación de temporalidad, concepto esencialmente inmobiliario. Gran parte de la regulación normativa del contrato de obra contenida en el Código Civil se refiere a la construcción, no solo por los alcances de sus disposiciones, tales como la regulación de las facultades de inspección y comprobación, sino por el contenido mismo de los textos normativos, en cuanto se hace explícita referencia a suelos, estudios, planos, edificación, etc. Pero sabemos también, y lo destaca el desaparecido profesor ARIAS SCHREIBER ${ }^{8}$, que no toda obra entraña construcción, ya que puede haber una "diversidad de matices": edificación de una casa, entrega de un cuadro, emisión de un dictamen, etc.; en dicho sentido, de ser asi, como lo es, bien podría delimitarse el campo de aplicación de los diversos artículos del Código Civil que regulan a este contrato ( $¿ T i e n e n$ sentido las facultades de inspección y comprobación para fines de una obra consistente en una opinión legal que pudiese ser encargada a un jurista, o cuando se encomienda confeccionar un terno?).

Somos concientes que el tema puede asociarse inclusive a la delimitación del objeto del contrato de locación de servicios y de obra (bastante imprecisa, a nuestro entender, en el Código Civil), pero consideramos que bien podría realizarse una labor interpretativa que permita identificar, por decirlo de alguna manera, la regulación del contrato de construcción.

Ahora bien, de asumirse (como es nuestro postulado) que el artículo 1784 del Código Civil solo resulta pertinente invocar tratándose de las obras consistentes en construcción (con vocación temporal o proyectadas y ejecutadas para "larga duración"), ello podría invitar además a sostener la tesis (que alguna vez nos ha sido expuesta) conforme a la cual el artículo en cuestión extiende temporalmente al saneamiento por vicios ocultos de uno a cinco años. Esto es, en el caso de muebles y de inmuebles que no son de larga duración, el plazo del saneamiento por defectos ocultos está regulado en la parte final del artículo 1783, mientras que"(...) tratándose de un edificio o de un inmueble destinado por su naturaleza a larga duración (...)", estaría regulado por el artículo 1784 del Código Civil. El argumento en cuestión puede ser seductor, pero no lo compartimos. Y nuestra discrepancia radica en que no debe olvidarse, de un lado, que el saneamiento por vicios ocultos solo admite el ejercicio de las acciones redhibitoria y estimatoria (según lo considere el afectado), y de otro lado, que el artículo 1784 del Código Civil regula un régimen de garantía que no es saneamiento por vicios ocultos, como consta de su propio texto.

Para concluir respecto a este tema de la temporalidad de la garantía, adviértase finalmente que

8 ARIAS SCHREIBER, Max y CÁRDENAS, Carlos, con la colaboración de ARIAS-SCHREIBER, Ángela y MARTINEZ, Elvira, Op. Cit., pp. 107 y 108. 
el cómputo del plazo no se inicia desde la construcción o terminación de la misma, sino desde la aceptación de la obra, sea expresa o tácita. Mientras puede ser discutible cuándo se tiene por construida una obra, la oportunidad de la aceptación resulta de inmediata y objetiva constatación en el calendario, de manera que desde la perspectiva de la técnica legislativa empleada nos parece un referente más apropiado.

2. Aunque no fluye de la redacción de la norma bajo comentario, consideramos que la responsabilidad quinquenal corresponde a un plazo de caducidad, por cuanto a su vencimiento queda liberado el contratista de la garantía de buena ejecución legalmente prevista, esto es, fenece el derecho del comitente de poder formular un reclamo por destrucción (total o parcial) del respectivo bien, o por amenaza de ruina o graves defectos constructivos.

Al ser un plazo de caducidad, resultan aplicables normas específicas en cuanto al cómputo del respectivo plazo, de manera particular el denominado "plazo fatal", sin olvidar lo concerniente a la fuente de su declaración constitutiva y su carácter rigurosamente continuo, que no admite -en principio- interrupción ni suspensión (artículos 2007, 2006 y 2005 del Código Civil, respectivamente).

Surge la cuestión sobre si resulta posible modificar dicho plazo, esto es, reducirlo o ampliarlo. De acuerdo a ARIAS SCHREIBER ${ }^{9}$, el plazo en cuestión puede ampliarse más no reducirse, ya que la ley garantiza un determinado mínimo, y lo garantiza en función a la durabilidad que se espera de una obra, más aún cuando reconoce que su aplicación "queda circunscrita casi totalmente a la práctica de la construcción". No compartimos dicho criterio sobre la posibilidad de poderse pactar un plazo mayor, porque no solo no logramos advertir su sustento en la redacción de la norma en cuestión, en la cual no se indica que se trate de un plazo "no menor" de cinco años, sino porque además (aunque debemos destacar que ARIAS SCHREIBER no sostiene que el plazo pueda ser considerado de caducidad) se estaría desconociendo los alcances del artículo 2004 del Código Civil, el cual establece que los plazos de caducidad los fija la ley ${ }^{10}$ sin posibilidad de pacto distinto, esto es, si la ley establece que la caducidad opera a los cinco años, es que opera a los cinco años, no a los tres ni a los siete, por lo que no hay posibilidad de pactar cosa distinta, no hay margen para la autonomía de la voluntad.

Ahora bien, en la negada hipótesis que se admitiera que el plazo no es de caducidad, debería admitirse que, por exclusión, el mismo sería de prescripción; sin embargo, en dicha hipótesis de trabajo, siendo que la determinación de los plazos de prescripción solo tiene por fuente a la ley (artículo 2000 del Código Civil), ¿Cómo podría sostenerse que las partes tienen la posibilidad de modificar lo que la ley ya estableció y acordar un plazo mayor? Ese pacto no sería legalmente viable.

Por último, ¿Por qué una responsabilidad quinquenal? El artículo 1784 del Código Civil tiene como antecedente legislativo inmediato al artículo 1556 del Código Civil de 1936, el cual establecía precisamente el plazo en cuestión, pero más allá de dicho dato, lo cierto es que uno puede preguntarse válidamente, ¿Por qué la responsabilidad del contratista derivada de destrucción, inminente ruina o graves defectos no podría extenderse a diez años, como ocurre tratándose del régimen similar previsto en el Código Civil argentino?, ¿Por qué se ha recortado de diez a cinco años el plazo de la acción personal para demandar esta responsabilidad especial del contratista? Nuestros comentaristas del Código Civil no extienden explicación

9 ARIAS SCHREIBER, Max y CARDENAS, Carlos, con la colaboración de ARIAS-SCHREIBER, Ángela y MARTÍNEZ, Elvira, Op. Cit., p.130.

10 Lo que no es lo mismo que afirmar que solo los fija la ley, de allí precisamente una diferencia entre los plazos de prescripción y de caducidad, conforme se aprecia de una lectura comparativa de los artículos 2000 y 2004 del Código Civil. 
ni opinión sobre este tema específico, lo cual genera ciertamente un vacío para definir luego cuáles son finalmente los intereses que resultan más beneficiados con una norma como la actualmente vigente. Sería interesante evaluar la conveniencia de establecer una responsabilidad decenal (teniendo presente que, en materia de obra pública, la responsabilidad es septenal) y de estructurar un régimen de responsabilidad objetivo, de manera que el contratista solo pueda liberarse demostrando fractura causal, ya que el mismo permite cumplir de mejor manera con la función reparatoria de la responsabilidad, pero ello ya es materia de un estudio más amplio y elaborado que escapa a los fines del presente ensayo.

3. Ahora bien, conforme ya hemos señalado anteriormente, no todos los contratos de obra están sujetos al período de responsabilidad quinquenal; tratándose de los contratos regulados por la Ley de Contrataciones y Adquisiciones del Estado ( $y$, en su momento, por la Ley de Contrataciones del Estado), los mismos están sometidos a un período mayor. Es así que el artículo 51 de la aún vigente Ley de Contrataciones y Adquisiciones del Estado (T.U.O. aprobado por Decreto Supremo No. 083-2004-PCM) ${ }^{11}$ establece una responsabilidad septenal; es más, se trata de un plazo que "no podrá ser inferior a siete años", con lo cual deja abierta la posibilidad que pueda pactarse un plazo mayor (a diferencia de la regulación civil), el cual entendemos que no debería ser mayor de diez años, por ser este el plazo de prescripción y/o caducidad más extenso reconocido por nuestra legislación (acción personal).

No obstante lo anterior, la redacción de la norma sobre contratación pública nos genera otro tema por analizar.

El artículo 51 en cuestión se refiere, tratándose específicamente de bienes, a los vicios ocultos,

11 Sobre el particular, el artículo 50 de la Ley de Contrataciones del Estado (Decreto Legislativo 1017) mantiene dicho plazo. el contratista mantiene responsabilidad por un plazo no menor de un año, desde la conformidad otorgada por la entidad, y en el caso de obra, que dicha responsabilidad es por un plazo no menor de siete años. ¿Esa responsabilidad corresponde al saneamiento? Si asumimos que dicha responsabilidad y el saneamiento son lo mismo, se estaría afirmando en buena cuenta que el artículo 51 de la Ley de Contrataciones y Adquisiciones del Estado regula el plazo para requerir el saneamiento por vicios ocultos, de manera que no se podría aplicar supletoriamente el plazo que ya hemos identificado conforme al Código Civil: artículo 1783, tercer párrafo, un año. Es más, admitir que se regula el plazo de saneamiento por vicios ocultos en la obra pública podría derivar en una relectura del artículo 1784 del Código Civil y, como consecuencia de ella, se plantee la misma tesis (en el sentido que el plazo no es de un año) por cuanto la norma establece que puede reclamarse si el bien presenta "graves defectos porvicio de la construcción". Todo ello significaría, en los hechos la posibilidad de discriminar entre vicios ocultos, sean graves o no. Es asi que tratándose de los graves, el plazo para el saneamiento sería de cinco años; tratándose de los que no son graves, solo un año, todo ello conforme a los artículos 1784 y 1783 del Código Civil.

Sobre el particular, consideramos que no procedería dicha relectura por una cuestión elemental. Si leemos con atención los alcances de los artículos 1784 del Código Civil y 51 de la Ley de Contrataciones y Adquisiciones del Estado podremos advertir que si bien ambos parten de la premisa de la existencia de un vicio oculto, no regulan el saneamiento que pudiese corresponder (bajo las vertientes de las acciones redhibitoria o estimatoria, según sea considerado por el comitente), sino que se refieren a la responsabilidad que corresponde ser asumida por aquello que ha derivado en la destrucción del bien, en su riesgo indubitable de destrucción o en graves defectos. En otras 
palabras, la responsabilidad regulada en la normas bajo comentario es ajena al tema del saneamiento. Eso quiere decir que el plazo para reclamar el saneamiento siempre es anual, con la naturaleza de plazo prescriptorio.

Conforme hemos señalado reiteradamente de manera precedente, vencido el plazo del saneamiento ya no procede reclamarlo por más que se haya advertido de un vicio oculto; sin embargo, a pesar que haya prescrito la respectiva acción, se mantiene la facultad de quien fue el comitente para hacer exigible la excepcional responsabilidad quinquenal (contratación privada) o septenal (contratación pública) del contratista, responsabilidad cuyo contenido no es el que corresponde al saneamiento.

4. Un tema que debemos analizar se refiere a los supuestos de aplicación de la norma bajo comentario; en efecto, el texto del artículo 1784 del Código Civil dispone un determinado régimen de responsabilidad cuando "la obra se destruye, total o parcialmente, o bien presenta evidente peligro de ruina o graves defectos por vicio de la construcción".

Ya hemos señalado que el antecedente inmediato del artículo bajo comentario es el artículo 1556 del Código Civil de 1936, el cual solo se refería al caso de "destrucción". El hecho que nuestro Código Civil vigente haya incorporado las nociones de "amenaza de ruina" y "graves defectos" no puede pasar inadvertido. Referencias a dichos conceptos existen en legislación comparada.

La destrucción del bien significa simple y llanamente su ruina, su desaparición, su destrozo, su desplome o derrumbe, sea total o parcial. Dicha situación fáctica acredita, en palabras de CASTALDI, "(...) un incumplimiento de la obliga- ción primordial del lociador. (...) El locador no ha cumplido las "reglas del arte". De lo contrario, la ruina no sobrevendría". ${ }^{12}$ Debe tenerse presente que la temporalidad no sólo es necesaria para fines de la ejecución de la obra contratada, sino que demás se espera duración del respectivo resultado; por ello es que consideramos (y así lo postulamos a lo largo del presente trabajo) que un régimen como el previsto en el artículo 1784 del Código Civil se aplica de manera específica para obras de edificación, respecto a inmuebles destinados por su naturaleza a una larga (razonable) duración.

Si la construcción se destruye, se desploma, no cabe duda que el contratista debe asumir responsabilidad. Otra cuestión será darle contenido a esa responsabilidad ( $¿$ Uno, cinco o diez años?, ¿Bajo un régimen subjetivo u objetivo?, etc.).

Nuestro Código Civil incorpora, para fines de aplicar el artículo bajo comentario la noción de "amenaza de ruina". La amenaza se refiere a una situación negativa inminente, un ataque, un daño. No se trata de una simple sospecha, sino de la seguridad que "algo" se va a producir. Este tema, debemos enfocarlo de la misma manera como se enfoca la noción de daño en materia de responsabilidad civil, lo cual nos permitirá comprender de una mejor forma los alcances de la expresión.

El daño no se presume. El daño debe probarse o acreditarse, debe ser cierto, para que, en su momento, pueda ser evaluado y mensurado para determinar finalmente la procedencia de la reparación reclamada y su quantum, de ser el caso. Ahora bien, conforme admite la doctrina, el daño cierto o efectivo, real, puede ser tanto presente como futuro, ya que la certidumbre no se refiere a su actualidad sino a su existencia. ${ }^{13}$

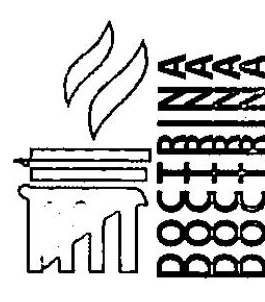

12 CASTALDI, José María, Contratos, Volumen II, Abeledo-Perrot, Buenos Aires, 1994, p. 213.

13 HENAO, Juan Carlos, El Daño, Universidad Externado de Colombia y Editorial Cordillera S.A.C., Lima, 2006, p. 130. 
En cuanto a la determinación del daño cierto, el mismo puede ser actual, evidenciado hoy en día, o futuro, en el sentido que su existencia recién se manifestará de manera diferida (pero se manifestará). Como bien expresa ZANNONI ${ }^{14}$ sobre esta materia:

"Pero para precisar el sentido exacto de estos conceptos, que pretenden traducir qué es lo que debe considerarse por daño existente -fuere actual o futuro-, es menester situarse, en primer lugar, en el plano del acaecer fáctico: considerar al daño como suceso que provoca la privación efectiva de un bien jurídico lo la provocará).

(...)

La certidumbre del daño, en suma, constituye siempre una constatación de hecho actual que proyecta, también al futuro, una consecuencia necesaria" (El subrayado es nuestro).

En esa misma línea de pensamiento, REY DE CASTRO $^{15}$ manifiesta que:

"En ocasiones el perjuicio no es actual, pues no ha acaecido, aunque se sabe de manera cierta que habrá de producirse en el futuro. ¿Tendrá la persona que va a sufrir ese daño el derecho a iniciar una acción indemnizatoria y obtener la reparación correspondiente al desmedro previsto? La solución afirmativa es la predominante, pese a las dificultades con que, necesariamente, se enfrentan los tribunales para considerar ineluctable el daño futuro y para fijar el quantum indemnizatorio del perjuicio que aún no ha ocurrido". (El subrayado es nuestro).

$\mathrm{Y}$ aunque el señalado autor comenta el régimen extracontractual de la responsabilidad civil, no hay inconveniente para aplicar dichos conceptos al ámbito contractual, dado que nos suscribimos a la tesis que en lo esencial el régi- men de daños es uno solo, conforme manifiesta WOOLCOTT en un lúcido análisis. ${ }^{16}$

En síntesis, los conceptos de "destrucción" y "amenaza de ruina" podemos asimilarlos, desde la óptica del Derecho de Daños, a lo que en la jurisprudencia francesa y modernamente se denomina "perjuicio consolidado" (simple comprobación o verificación de lo actual o de una realidad ya vivida, daño actual o presente) y "perjuicio no consolidado", respectivamente, aunque de este último nos interesa únicamente el "perjuicio no consolidado a partir de una situación existente" (daño futuro). Siendo que, con relación a este último:

"(...) la certeza del perjuicio proviene de que la situación sometida a estudio existe ya en el momento en que el juez hace la calificación. En estos casos el juez no califica la probabilidad de la situación, pues esta existe ya en el momento de la operación intelectual. Lo único que el juez hará será juzgar la certeza de su prolongación en el tiempo". ${ }^{17}$ (El subrayado es nuestro).

Si bien podría interpretarse que al poder reclamarse "destrucción" puede hacerse también lo mismo con la "amenaza de destrucción" (en la medida que se pueda demostrar que el daño existe, siendo solo una cuestión de temporalidad su evidencia material), consideramos que el Código Civil con muy buen criterio ha optado por mencionar explícitamente ambas situaciones, asegurando de dicha manera los derechos del comitente, quien podrá reclamar por el daño cierto presente (evidenciado materialmente: destrucción de la obra), o por el daño cierto futuro (existente, pero que no se ha evidenciado aún materialmente: amenaza de desplome o de ruina). Conforme se aprecia, en ningún caso podría válidamente reclamarse por una mera sospecha de ruina, ya que ello sería un presunto daño, hipotético o conjetural; la amenaza de

14 ZANNONI, Eduardo, EI Daño en la Responsabilidad Civil, Editorial Astrea de Alfredo y Ricardo Depalma S.R.L., Buenos Aires, 1982, pp. 24 y 25.

15 REY DE CASTRO, Alberto, La Responsabilidad Civil Extracontractual, Universidad Nacional Mayor de San Marcos, Lima, 1972, p. 313.

16 WOOLCOTT, Olenka, La Responsabilidad Civil de los Profesionales, ARA Editores, Lima, 2002, pp. 234 a 317.

17 HENAO, Juan Carlos, Op. Cit., p. 137. 
desplome o caída de la edificación es daño cierto porque ya existe la afectación al interés del comitente, siendo solo una cuestión de tiempo su materialización (de lo contrario se pondría en entredicho la causalidad, que es otro de los presupuestos de la responsabilidad civil).

Por último, el tercer supuesto para la procedencia de la exigibilidad de la responsabilidad quinquenal corresponde a "graves defectos" de lo ejecutado. Los defectos corresponden a vicios, conforme ya hemos señalado en su oportunidad.

¿Cuáles son estos "graves defectos" que podrían dar paso al régimen de responsabilidad contenido en el artículo 1784 del Código Civil?

Se trata, en primer lugar, de graves vicios ocultos o internos, no constatables con ocasión de haberse recibido el respectivo bien (en nuestra opinión, de manera concreta y específica, la edificación). Y en segundo lugar, no se trata de cualquier grave defecto latente, ya que postulamos la tesis que el artículo 1784 del Código Civil solo se aplica para determinados vicios ocultos. Nos explicamos. Debe partirse del hecho que la responsabilidad exigible se justifica por cuanto el bien adolece de graves defectos que afectan su valor o utilidad, de tal manera que habrá que mensurarse en cada caso particular lo que se entiende por grave o no.

Ahora bien, de asumirse dicho criterio, postulamos que también debería admitirse que el régimen de responsabilidad solo operaría por los defectos ocultos y graves que han surgido una vez que habría prescrito el plazo para reclamar por vicios ocultos (artículo 1783 del Código Civil) para no dejar en indefensión a quien fue el comitente.

En otras palabras, si el grave vicio oculto en cuestión surgió dentro del año de construida la obra, y no fue reclamado por el interesado, consideramos que operó la prescripción para exigir el saneamiento, no pudiéndose reclamar responsabilidad posteriormente bajo el artículo 1784 del Código Civil, por cuanto hubo -por decirlo de alguna manera- una asunción volun- taria de riesgo, hubo negligencia del comitente en accionar oportunamente para hacer valer sus derechos. Sin embargo, si el vicio oculto recién se manifiesta una vez que ha vencido el plazo anual de prescripción (lo cual determina que no podrá exigirse saneamiento alguno), y en la medida que se trate de un vicio oculto de naturaleza grave (que afecte la existencia de los edificios e inmuebles de "larga duración"), excepcionalmente podrá reclamarse la responsabilidad del contratista considerando que la obra está teóricamente llamada a mantenerse en el tiempo (duración sostenida).

Consideramos que una interpretación en los términos precedentes permitiría definitivamente que no exista posibilidad de superposición entre los regímenes de saneamiento por vicios ocultos y por responsabilidad quinquenal (o septenal), siendo que también permitiría valorar adecuadamente los comportamientos contractuales (diligencia en las actuaciones), equilibrando los intereses comprometidos.

En alguna oportunidad se nos ha manifestado que los supuestos de responsabilidad regulada por el artículo 1784 del Código Civil son dos y solo dos; destrucción o amenaza de destrucción, siendo que el "grave defecto por vicio de la construcción" es lo que explicaría la ruina o inminente ruina, como podría ser también otra explicación lo referente a los materiales o a los estudios realizados. En otras palabras, siendo que la obra no solo es un contrato de duración sino que se espera duración respecto de lo ejecutado, se consagraría un régimen para cautelar el interés del comitente en los únicos casos en que se destruya lo ejecutado o esté en riesgo de destrucción. Los defectos, por más graves que sean, en la medida que no representen evidencia de una amenaza de ruina, no serán relevantes para el régimen de responsabilidad bajo comentario; con relación a ellos, solo se aplicaría el régimen de saneamiento.

El problema de dicha tesis, cuyo enunciado suena interesante, es que se está obviando el tenor del artículo 1784 bajo comentario, el cual se refiere indistintamente a "destrucción", "evidente peligro de ruina" o "graves

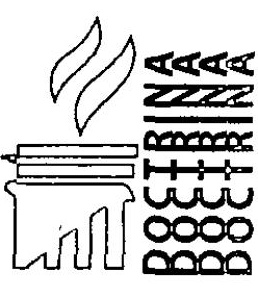

青 
defectos", siendo que cualquiera de ellos debe explicarse (elemento de la causalidad para fines de la responsabilidad) por "vicios de la construcción"; asociar exclusivamente los vicios constructivos a los graves defectos no está legalmente previsto y desnaturalizaría los alcances de la norma comentada, por cuanto la existencia de los graves defectos pueden significar que la obra sea inútil para los fines previstos o a los que corresponden ordinariamente. No habría razón para proteger al comitente solo en los casos de destrucción o de deterioro grave, igual protección merece ante graves defectos.

En sintesis. No se trata solo que la obra se destruya o que amenace destrucción, sino que también presente graves, serios defectos. Habrá que confiar en un adecuado criterio jurisdiccional que impida que este régimen de responsabilidad se aplique indiscriminadamente, y para ello postulamos la tesis ya expuesta en el sentido que los graves vicios ocultos deben haberse evidenciado una vez que ha prescrito la acción por saneamiento.

5. ¿Cómo hacer efectiva la responsabilidad imputada al contratista? El artículo 1784 del Código Civil establece la necesidad que el comitente avise por escrito de fecha cierta dentro de los seis meses siguientes al descubrimiento.

¿Se trata de una formalidad necesaria o no? La cuestión se plantea por cuanto en el primer párrafo del artículo en cuestión (en el cual está establecido la necesidad del aviso de fecha cierta) se señala: "Todo pacto distinto es nulo", lo cual evidencia una disposición imperativa, de ineludible cumplimiento.

El tema tiene particular relevancia porque en cierto caso real, en el cual hemos tenido determinada participación profesional, la comunicación de la existencia del vicio oculto se realizó mediante simple medio escrito, de allí que una vez que se demandó que se hiciera efectiva la respectiva responsabilidad, el primer argumento de defensa del emplazado fue que no se había cumplido con el aviso de ley y, por lo tanto, que había caducado el derecho del comitente para reclamar la responsabilidad quinquenal. Lo curioso es que el emplazado se acogía a un argumento "formal" aunque reconocía haber recibido el aviso e inclusive haberlo respondido.

En dicha sentido, y a mayor abundamiento, se sostiene que al establecerse legalmente la nulidad de todo pacto distinto, ello se extiende en general a los alcances de toda la norma y, en particular, al hecho que las partes no podrían válidamente acordar que el aviso se realice bajo cualquier otra modalidad que carezca de fecha cierta, y menos aún que una de las partes realice el respectivo aviso -sin observar la exigencia legal de fecha cierta- y pretenda que el mismo sea válido y eficaz. $Y$ desde otra perspectiva, se distingue lo que es el acto en sí (el aviso) y las consecuencias del mismo, considerándose que puede haberse realizado el aviso (evitándose discutir la validez del mismo) pero no surte efectos jurídicos por cuanto no observa la exigencia imperativamente prevista en el artículo 1784 del Código Civil.

Entendemos que cuando el artículo 1784 del Código Civil -cuyo carácter imperativo está fuera de discusión- establece que "Todo pacto distinto es nulo", se refiere a que las partes no pueden establecer que el régimen de responsabilidad pueda ser exigido de manera distinta a la enunciada, como sería el caso de acordar una reducción del plazo quinquenal, ya que si concordamos dicha norma con lo establecido en el artículo 2004 del Código Civil, podremos advertir que los plazos de caducidad legalmente fijados no permiten pacto en contrario. Es más, la prohibición del pacto en contrario se interpreta en el sentido que el régimen de responsabilidad del contratista no puede reducirse ni disminuirse, más si puede convenirse uno más estricto, más riguroso, pero sin que en ningún caso se suprima la garantía establecida 
por el contratista a favor del comitente. ${ }^{18}$ Dicha lectura podría resultar cuestionable por cuanto el régimen de responsabilidad pactado en términos más onerosos, que sobrepasen al legal, representaría estrictamente un pacto distinto al régimen previsto. Alli surge la cuestión, eminentemente interpretativa sobre los alcances de las expresiones "Todo pacto en contrario es nulo" y "Todo pacto distinto es nulo", lo cual hace ciertamente apasionante el ejercicio de nuestra profesión, atendiendo que dichas frases pueden desarrollarse con distintos significados para salvar una situación de nulidad. Habrá que ver en cada caso, cuándo se afecta la "ratio legis". $Y$ desde ya anticipamos nuestra posición en el sentido que la expresión "Todo pacto distinto es nulo" se refiere a ciertos aspectos, reglas, normas, contenidas en el artículo 1784 del Código Civil, no siendo aplicable a todas y cada una de ellas.

Así, en primer lugar, debe tenerse presente que siendo el aviso "de fecha cierta" una declaración de voluntad, para fines de su exteriorización o forma, la misma puede ser solemne ("ad solemnitatem") o probatoria ("ad probationem"). La forma solemne es necesaria para la validez del acto. La forma probatoria no lo es, pero es útil para probar la existencia del negocio o la declaración misma, útil más no indispensable (ni siquiera para la eficacia), por cuanto en este último caso, se tornaría indirectamente en forma necesaria; no se trata de una forma impuesta sino aconsejada ${ }^{19}$, por lo que de no observarse la misma, se asumirá la carga probatoria de tener que acreditar la oportunidad en que se cumplió realmente con realizar la respectiva comunicación.

Asimismo, debe considerarse que las normas legales deben leerse e interpretarse sistemáticamente. El artículo 144 del Código Civil esta- blece expresamente que, de mediar indicación de forma, más de no sancionarse con nulidad su inobservancia, representa solo un medio de prueba, esto es, la existencia del acto se puede probar de cualquier manera, entre ellas, bajo la forma señalada por la ley con carácter simplemente "ad probationem". Por ello es que ARIAS SCHREIBER, ponente del contrato de obra en el proceso de elaboración del actual Código Civil, manifiesta que "El escrito de fecha cierta a que se refiere el primer párrafo del artículo 1784 es ad probationem, en virtud de lo dispuesto en el artículo 144 del Código Civil". ${ }^{20}$

De manera complementaria a lo expuesto, para determinar si se está ante un elemento constitutivo de la declaración o ante un simple medio de reconocimiento de la misma, debe también considerarse que los efectos del aviso regulado en el artículo 1784 del Código Civil se asocian a una situación de caducidad y, por lo tanto, presentan una naturaleza restrictiva, limitante de derechos, lo cual deriva que, conforme a la doctrina y a nuestra propia legislación (artículo IV del Título Preliminar del Código (ivil), no correspondía realizarse aplicaciones por analogía (e inclusive de carácter restrictivo). Desde esa perspectiva, si la sanción de nulidad no está expresamente señalada para el caso bajo comentario, no podría aplicarse por analogía o extensivamente, más aun cuando la sanción misma de nulidad es conceptualizada de manera restrictiva, en "numerus clausus".

Además, merece destacarse que el artículo 1784 bajo comentario contiene un procedimiento operativo similar al regulado en la parte final del artículo 1783 del Código Civil. En efecto, la norma dispone que el comitente debe dar aviso (escrito de fecha cierta) al contratista dentro de los seis meses siguientes al descubrimiento

18 TOVAR GIL, María del Carmen y FERRERO, Verónica. En: Código Civil comentado, Tomo IX, Gaceta Jurídica S.A., Segunda Edición, Primera Reimpresión, Lima, 2007, pp. 181 a 184.

19 LOPEZ DE ZAVALIA, Fernando, Teoría de los Contratos, Tomo I (Parte General), Tercera Edición, P. DE ZAVALÍA, Victor, Editor, La Plata, República Argentina, 1984, p. 196.

20 ARIAS SCHREIBER, Max y CÁRDENAS, Carlos, con la colaboración de ARIAS-SCHREIBER, Ángela y MARTÍNEZ, Elvira, Op. Cit., p. 131. 
(del grave defecto, de la amenaza de ruina o de la destrucción del bien), debiendo interponer la acción dentro del año siguiente al señalado aviso. A diferencia del artículo 1783 del Código Civil no se indica si los plazos señalados son de prescripción o de caducidad. Somos de opinión que, ante situaciones semejantes, la solución jurídica no debe diferir. En dicho sentido, el plazo de seis meses (para el aviso) debería considerarse como uno de caducidad (tomando el criterio del artículo 1783 del Código (ivil), mientras que el plazo anual (para el ejercicio de la acción) sería de prescripción.

Por último, ¿Cómo explicar que la disposición sobre "Todo pacto en contrario es nulo" se aplica a ciertos aspectos del artículo 1784 del Código Civil (alcances de la responsabilidad, conforme hemos expresado precedentemente) y no a otros (tema del aviso mediante el cual se comunica el descubrimiento de los vicios? Consideramos que la respuesta es sencilla: el artículo 1784 en cuestión contiene diversas reglas o normas legales. ${ }^{21}$ No podemos caer en el facilismo de considerar que cada artículo del Código Civil contiene una sola norma. Lo concerniente al aviso es una norma supletoria. Tratándose de la responsabilidad exigible, la norma es supletoria dentro del marco legal sobre el factor de atribución, ya que en el contexto de los contratos paritarios, todo acuerdo que excluya o limite la responsabilidad por dolo o culpa inexcusable es nulo ${ }^{22}$, por lo que respecto a estos factores de atribución la norma es imperativa. Pero tratándose de las causales por las cuales es exigible la responsabilidad: destrucción, peligro de ruina y graves defectos constructivos, consideramos que la norma no solo es imperativa sino que sanciona adicionalmente con nulidad acuerdo distinto por el cual se pretenda desconocer los casos de responsabilidad legalmente exigibles. Por ello, si seguimos esta interpretación podemos concluir, como ya hemos señalado anteriormente, que sí se puede convenir un régimen de responsabilidad contractual más estricto, más riguroso (por ejemplo, sujeto a responsabilidad objetiva), pero sin que en ningún caso se suprima la garantía establecida a favor del comitente en los casos legalmente previstos.

En síntesis, y a manera de conclusión, por la naturaleza de las cosas, el plazo quinquenal (o septenal) dentro del cual puede pretenderse hacer efectiva la responsabilidad del contratista es uno de caducidad, conforme ya hemos expresado. Demás está decir que si al vencimiento del quinto año desde la aceptación de la obra no se ha librado el aviso (sea de fecha cierta o no) sobre el descubrimiento del grave defecto, de la amenaza de ruina o de la destrucción del bien, por más que aún no haya vencido el plazo de seis meses reconocido para dicho efecto, caduca toda posibilidad de reclamo frente al contratista. Asimismo, si dentro de los cinco años desde la aceptación, por más que se haya cumplido con el aviso oportuno dentro de los seis meses del descubrimiento del grave defecto, no se ha emplazado al contratista de la demanda de responsabilidad, para lo cual se dispone de un año desde el aviso, también consideramos que habría caducado toda posibilidad de reclamo. De lo contrario, estaríamos ampliando el plazo de caducidad legalmente establecido, lo cual es jurídicamente imposible.

6. ¿Cuál es el contenido de la responsabilidad contractual regulada en el artículo 1784 del Código Civil?

21 Resulta pertinente destacar que DIEZ PICAZO, Luis y GULLÓN, Antonio (En: Sistema de Derecho Civil, Volumen I, Editorial Tecnos, Madrid, 1988, p. 55) expresan, respecto a esta dicotomía norma/articulo, que la norma juridica no se encuentra necesariamente contenida en un solo artículo o disposición legislativa, por lo que resulta necesario muchas veces realizar la necesaria conexión entre diversos textos para identificarla o reconstruirla; de la misma manera, asi como la norma jurídica puede estar desagregada en varios articulos de una ley, bien puede también un solo artículo contener diversas normas jurídicas.

22 Artículo 1328 del Código Civil. Tratándose de la contratación no paritaria, nos remitimos al artículo 1398 del mismo cuerpo legislativo. 
ARIAS SCHREIBER expresa "El artículo 1784 no aclara el tipo de acción que corresponde al comitente y si abarca la reconstrucción total o parcial y la eliminación del peligro de ruina o graves defectos de construcción, en su caso, o si simpley llanamente se limita a la reparación de los daños y perjuicios. Nosotros creemos que por la naturaleza de las cosas y el interés que se cautela el comitente podrá actuar con la máxima flexibilidad, de modo que nada le impedirá solicitar la reconstrucción - la eliminación de la ruina, o de los defectos de construcción, sin desmedro de que reclame los daños y perjuicios que se le han causado."23

Resulta casi imposible no coincidir en este tema con el citado autor, pero consideramos pertinente realizar ciertos comentarios complementarios. En primer lugar, estimamos que una reclamación por daños y perjuicios no debe enfocarse necesariamente como un tema pecuniario, ya que la modalidad de la reparación reclamada se sustenta en el interés del perjudicado, en nuestro caso, del comitente; en razón de ello, presentar como temas diferenciados la reconstrucción y la reparación por daños, representa un criterio que no compartimos necesariamente. En segundo lugar, debemos destacar que, conforme ya hemos explicado, los alcances del artículo 1784 del Código Civil son distintos a los del artículo 1783; por lo tanto, no es posible considerar que la solución contenida en la norma bajo comentario pueda ser la misma que se derivaría del último párrafo del artículo 1783 del Código Civil, ya que este se refiere al saneamiento por vicios ocultos $y$, por ende, legitima a interponer oportunamente la acción redhibitoria o la acción estimatoria, no hay más. La acción que se desprende del artículo 1784 del Código Civil es una derivada por daños y perjuicios de índole contractual, con la singularidad que no está sujeta al plazo de prescripción decenal de las acciones personales. $Y$ el tercer lugar, al tratarse de una acción esencialmente reparatoria, no procede acción resolutoria alguna, ya que esta es posible en el contexto del saneamiento por vicios.ocultos (tema ajeno a la norma bajo comentario), más aún cuando por una cuestión de temporalidad el contrato ya quedó concluido al haberse entregado el bien, de tal manera que no podría resolverse lo inexistente.

\section{COMENTARIO FINAL}

Hemos tratado de exponer algunos de los tantos temas respecto de los cuales pueden sostenerse diversos enfoques, expresando nuestras inquietudes y postulando ciertas tesis interpretativas sobre los alcances del artículo 1784 del Código Civil, de particular importancia tanto en el ámbito de la obra privada como pública.

Corresponde a quienes ejercen función jurisdiccional, sea en lo judicial o en lo arbitral, sobre todo por la estrecha relación de esta última con la contratación pública, perfilar de la mejor manera los supuestos de aplicación de las diversas normas legales, lo cual supone en definitiva optar por una determinada interpretación, considerando una serie de elementos: finalidad de la norma, alcances sistemáticos, intereses sociales comprometidos, utilidad práctica, etc.

Confiamos que al compartir nuestras reflexiones, $y$ descubrir además nuestras propias limitaciones, podamos motivar a una lectura inquisitiva sobre la regulación del contrato de obra, en especial tratándose del artículo 1784 del Código Civil. Si luego de ello, contrastando este ensayo con otras posiciones, el lector hace suya algunas tesis propuestas, bien; pero si tiene finalmente más preguntas que respuestas, mejor, este ensayo habrá cumplido ampliamente su propósito.

Parafraseando lo que en alguna oportunidad se afirmó: "Hablar debemos, callar no podemos, (...) esperamos no quedarnos solos al hablar".

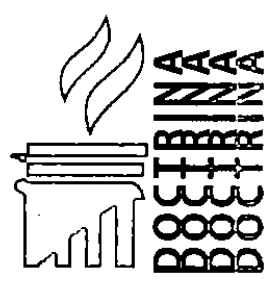

23 ARIAS SCHREIBER, Max y CARDENAS, Carlos, con la colaboración de ARIAS-SCHREIBER, Ángela y MARTíNEZ, Elvira, Op. Cit., p. 130. 